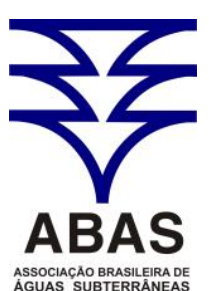

ASSOCIACAO BRASILEIRADE www.abas.org

\section{SIMULAÇÃO NUMÉRICA MULTIFÁSICA DE FLUIDO DE PERFURAÇÃO E DE TRANSPORTE BENZENO EM POÇO DE PETRÓLEO NA BAHIA, BRASIL}

\author{
NUMERICAL SIMULATION OF MULTIPHASE FLUID DRILLING AND \\ TRANSPORT OF BENZENE IN AN OIL WELL IN BAHIA, BRAZIL
}

Elias Hideo Teramoto ${ }^{1}$, Everton de Oliveira ${ }^{2}$, Chang Hung Kiang ${ }^{3}$, Alex Tadeu de Almeida Waldmann ${ }^{4}$, Ricardo Luiz de Campos Vaqueiro ${ }^{5}$ Helder dos Santos ${ }^{6}$

Artigo recebido em: 18/10/2013 e aceito para publicação em: 24/02/2014.

\begin{abstract}
Drilling fluids with varied chemical composition are used in oil well industry due to their specific properties with respect to the well particular characteristics. Environmental concern led the oil industry to research and produce fluid compositions that are potentially harmless to the environment and at the same time, offer similar performance to the former fluids based on diesel oil. This document shows simulations of the fluid emulsion based on hydrogenated n-paraffin with water, based on a case study at the São Sebastião Aquifer, in the Bacia do Recôncavo, Bahia. Among the compounds that form the n-paraffin fluid there are trace concentrations aromatic group BTEX (benzene, toluene, ethylbenzene and xylenes) of environmental concern. Numerical simulation was divided in two phases: a) multiphase: where the n-paraffin fluid invasion of the geological formation immediately adjacent to the drilling wall indicated that the fluid would reach a distance of $15 \mathrm{~cm}$ from the wall with maximum saturation of $60 \%$ of the porous medium; b) transport: from the previous results, it was simulated the fate of dissolved benzene, which indicated that it could reach a distance of $3,0 \mathrm{~m}$ from the well wall where concentrations were under CETESB's intervention values (CETESB, 2005).
\end{abstract}

Keywords: n-paraffin fluid. Multi-phase flow. São Sebastião Aquifer. MT3D. Fluid invasion. Benzene.

Resumo: Na perfuração de poços para extração de petróleo são utilizados fluidos de perfuração compostos por diversos produtos químicos com finalidades específicas em função das características de cada poço. O aumento da preocupação com possíveis danos ambientais levou a indústria do petróleo a trabalhar em composições de fluidos de perfuração ambientalmente seguros e que, ao mesmo tempo, apresentem desempenhos semelhantes aos fluidos anteriormente usados à base de óleo diesel. Neste trabalho foram simulados os efeitos da utilização do fluido de emulsão base n-Parafina hidrogenada com água emulsionada, ou "n-parafina" neste documento, tomando-se como estudo de caso do Aquífero São Sebastiao, na Bacia do Recôncavo, Bahia. Entre os compostos presentes na composição deste fluido específico, destacam-se concentrações-traço dos compostos orgânicos aromáticos BTEX (benzeno, tolueno, etilbenzeno e xilenos), de interesse ambiental.

A simulação foi dividida em duas etapas: a) multifásica, considerando a abrangência da invasão do fluido n-parafina na formação imediatamente adjacente à perfuração, indicando que o fluido poderá atingir uma distância de $15 \mathrm{~cm}$ a partir da parede da perfuração, com saturação máxima de n-parafina no meio poroso de $60 \%$, aproximadamente; b) transporte, a partir do resultado anterior, foi simulado o comportamento do benzeno dissolvido, cujos resultados indicaram que o contaminante poderá se mover a uma distância de 3,0 m a partir da parede do poço, até que suas concentrações declinem abaixo dos valores de intervenção da CETESB (2005).

Palavras-chave: Fluido de emulsão base n-parafina. Fluxo multifásico. Aquífero São Sebastião. MT3D. Invasão de fluido. Benzeno.

\title{
INTRODUÇÃO
}

Dentre as atividades potencialmente poluidoras das águas subterrâneas encontram-se as atividades relacionadas à perfuração de poços para extração de petróleo pelo método tradicional

\footnotetext{
${ }^{1}$ LEBAC - Laboratório de Estudo de Bacias (eh_teramoto@yahoo.com.br).

${ }^{2}$ LEBAC - Laboratório de Estudo de Bacias (everton@ hidroplan.com.br).

${ }^{3}$ LEBAC - Laboratório de Estudo de Bacias (chang@ @rc.unesp.br).

${ }^{4}$ CENPES - Petrobras (awaldmann@ @etrobras.com.br).

${ }^{5}$ Petrobras (vaqueiro@ petrobras.com.br).

${ }^{6}$ Petrobras (helder.santos@ petrobras.com.br).
} 
(não fracking), tendo em vista que sua execução pode envolver o manuseio de substâncias nocivas ao ambiente. No início da década de 90, ocorreu a proibição da utilização de fluidos a base de óleo diesel nas atividades de perfuração de poços no Golfo do México e no Mar do Norte para evitar impactos à fauna marinha em seu entorno, que precedeu a sua proibição em diversas partes do mundo.

Tal orientação também foi adotada para as perfurações terrestres, onde as companhias de petróleo buscaram substitutos ao diesel utilizado na composição dos fluidos de perfuração. A Petrobras realizou pesquisas destinadas a encontrar um composto eficiente na perfuração de poços e que não oferecessem riscos de contaminação dos aquíferos presentes na Bacia do Recôncavo. Após levantamento bibliográfico e testes realizados, optou-se pelo fluido n-parafina $\mathrm{C} 13+$, que apresentou excelentes resultados relativos à viscosidade, limite de escoamento, toxicologia e danos à formação.

Obedecendo às determinações do órgão ambiental do Estado da Bahia, a Petrobras tem utilizado fluidos de perfuração à base de água nas fases iniciais dos poços, em detrimento do fluido de emulsão base n-parafina. Embora muitos dos fluidos à base de água possuam riscos de contaminação potencialmente menores, dificilmente se consegue reaproveitá-los, ao contrário do fluido base n-parafina. Este fato tem sido responsável pela geração de um grande volume de efluentes que devem ser corretamente descartados, criando um novo ônus ambiental e econômico. Além do aumento do tempo de perfuração e riscos à estabilidade do poço, inerentes a utilização do fluido a base água.

\section{OBJETIVOS}

Este trabalho visa avaliar os riscos envolvidos no aquífero São Sebastião durante a perfuração de poços de para extração de petróleo em campos terrestres, em função da natureza do fluído empregado na perfuração e nas características hidráulicas deste aquífero. Para alcançar os objetivos aqui propostos, foram realizadas simulações numéricas de fluxo multifásico para determinar a dimensão do avanço do fluído de perfuração no aquífero, bem como simulações numéricas de transporte de solutos eventualmente presentes nestes fluídos, com vistas a avaliar o comportamento das plumas de benzeno potencialmente geradas.

\section{CONTEXTO GEOHIDROGEOLÓGICO}

A Formação São Sebastião, unidade litoestratigráfica da Bacia Sedimentar do Recôncavo, que é formada por depósitos de coberturas fanerozóicas, de idade juro-cretácica, inserida no contexto do Rift Recôncavo - Tucano - Jatobá, teve sua evolução iniciada no Cretáceo Inferior, ao se tornar um braço abortado do rifteamento que originou o Atlântico Sul (VIANA et al., 1971). A gênese da Formação São Sebastião está relacionada a um contexto deposicional flúvio-deltaico, que é 


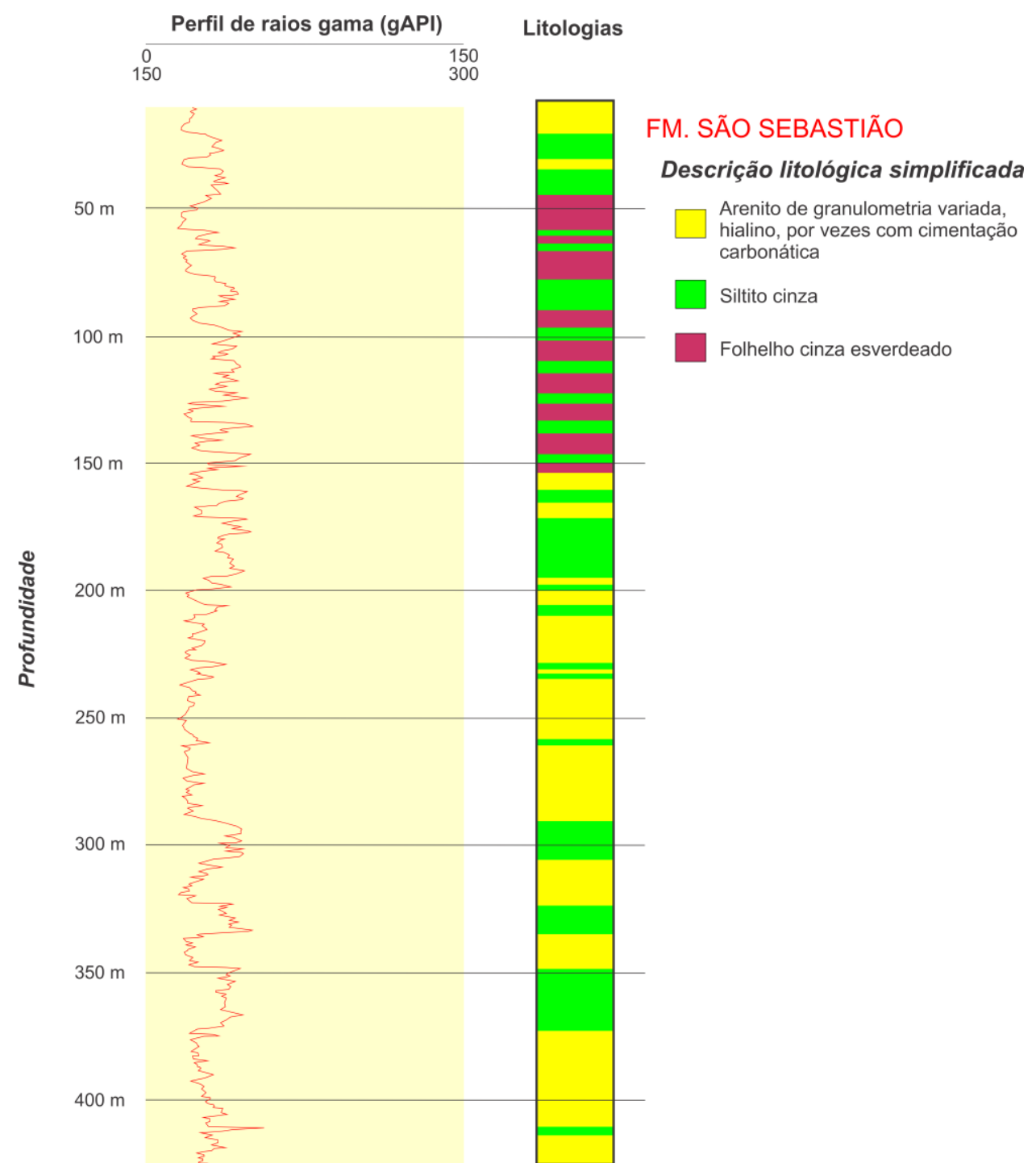

Figura 1 - Perfil de raios gama e litológica de uma sucessão típica da Formação São Sebastião, marcada pela alternância de litologias arenosas e pelíticas

Figure 1 - Lithologic and gamma-ray profile of a typical succession of the San Sebastian Formation, characterized by sandy and pelitic rock alternation

Desta forma, o aquífero São Sebastião é representado por um sistema multi-camadas com aproximadamente $1.500 \mathrm{~m}$ de espessura saturada, com uma área de recarga de $6.583 \mathrm{Km}^{2}$. Em geral, verifica-se que a água do aquífero São Sebastião na porção superior do aquífero é de ótima qualidade, deteriorando-se próximo à sua porção basal. A porção superior do São Sebastião é representada por um aquífero livre, enquanto em porções profundas, o aquífero é confinado em virtude da presença de intercalações com espessas camadas de litologias pouco permeáveis a impermeáveis (LIMA, 1995).

No que se refere às propriedades hidráulicas do aquífero, Cunha et al., (1986), verificaram que aquífero São Sebastião apresenta um valor de transmissividade média de $5 \times 10^{-3} \mathrm{~m}^{2} / \mathrm{s}$, condutividade hidráulica média de $2,7 \times 10^{-5} \mathrm{~m} / \mathrm{s}$ e coeficiente de armazenamento de $4 \times 10^{-5}$. Complementarmente, Vaqueiro (2006) verificou que o valor médio de porosidade dos arenitos da Formação São Sebastião é de 0,30.

Regionalmente, o gradiente hidráulico é relativamente baixo, em torno de 0,0035 , que é consistente com elevados valores de condutividade hidráulica associados às camadas arenosas da Formação São Sebastião. A direção de fluxo subterrâneo preferencial é de W-NW para E-SE, coincidente, portanto, com o mergulho regional dos estratos (Figura 2). 


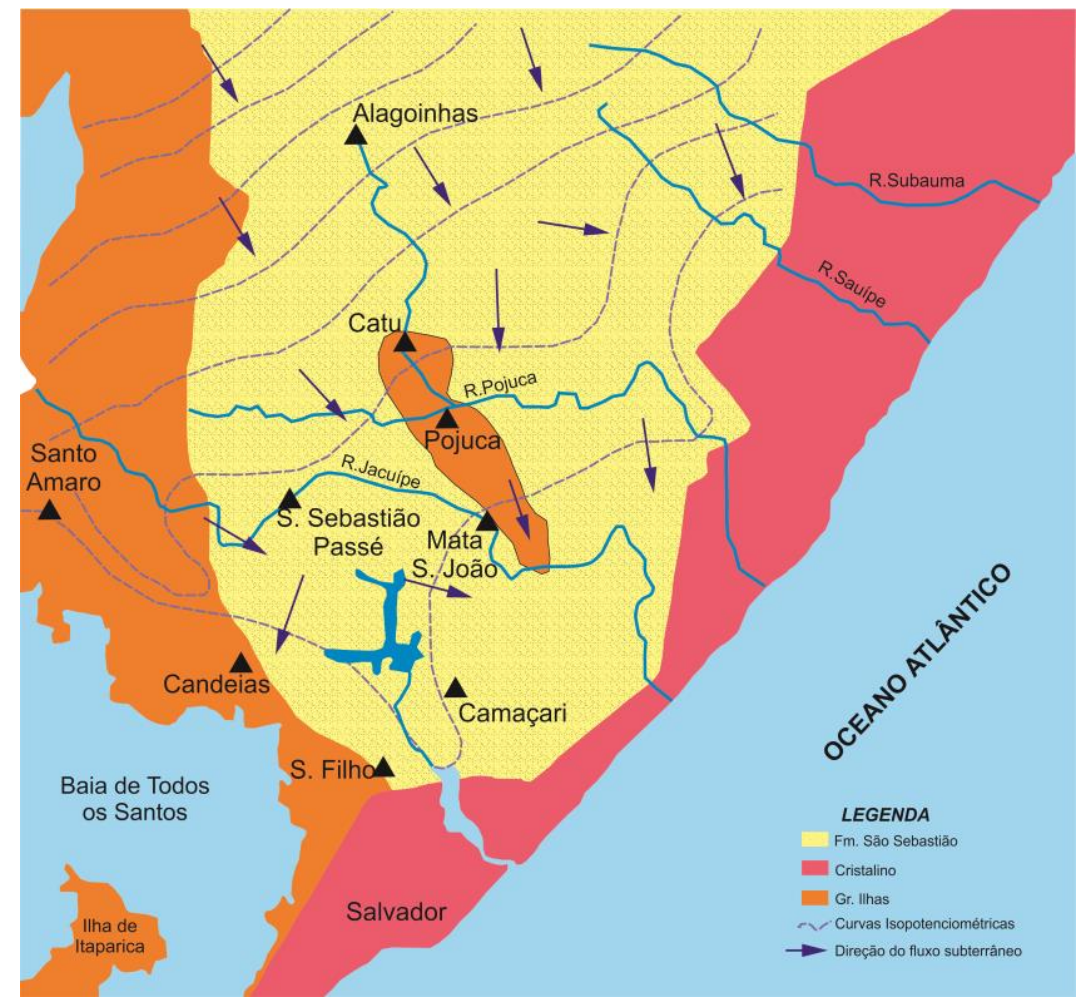

Figura 2 - Direção de fluxo e linhas isopotenciométricas no Sistema Recôncavo ( Modificado de Leão, 2003)

Figura 2 - Flow direction and potentiometric lines in the Reconcavo System (Modified from LEÃO, 2003)

\section{FLUIDOS DE PERFURAÇÃO}

Os fluidos de perfuração representam elementos cruciais na perfuração dos poços de extração de petróleo e seu desenvolvimento permitiu o aprimoramento das técnicas de perfuração rotativa. Estes fluidos são misturas complexas de sólidos, líquidos e, por vezes, até gases, que, do ponto de vista químico, podem assumir aspectos de suspensão, dispersão coloidal ou emulsão, dependendo do estado físico dos componentes (LIMA, 2001). Os fluidos de perfuração são injetados por meio de uma bomba de lama por dentro do tubo de perfuração e retorna pelo espaço anular entre a coluna e a parede do poço.

Inicialmente, o próprio petróleo era a base utilizada na confecção de fluidos de perfuração, tendo sido posteriormente substituído pelo óleo diesel, largamente utilizado até o início da década de 80. Apesar da presença de outros componentes no fluido, o componente responsável pela sua toxicidade é a sua base não-aquosa. Com o aumento da preocupação dos riscos de contaminação ambiental, devido à presença do óleo diesel na composição do fluido, iniciou-se a busca de fluidos que fossem adequados do ponto de vista ambiental mas que mantivessem seu desempenho, surgindo então o uso de óleo mineral convencio- nal, também conhecido como parafina líquida ou óleo branco, óleo mineral melhorado, éster e hidrocarbonetos sintéticos (alfaoleifinas lineares, polialfaoleifinas e oleifinas internas).

É possível classificar os fluidos de perfuração segundo o constituinte principal da fase contínua (ou dispersante) em fluidos de base aquosa e fluidos de base não-aquosa. Os fluidos de base não-aquosa são aqueles que apresentam compostos de reduzida miscibilidade em água como fase contínua, e a água como fase dispersa. Estes fluidos também são chamados de emulsão inversa, uma vez que as gotas de água ficam encapsuladas pelo óleo ou outro composto, tendo maior dificuldade de interagir com as camadas argilosas.

Um importante papel desempenhado pelos fluidos de perfuração é a formação do reboco, que consiste em uma zona de baixa permeabilidade nas paredes do poço pela aglutinação de partículas sólidas presentes no fluido, cuja finalidade é a prevenção do inchamento de argilas hidratáveis pela entrada da fração aquosa deste fluido (DARLEY E GRAY, 1988). Em razão deste fato, tornase desejável inibir o influxo da fração aquosa do fluido de perfuração, denominada de filtrado. 
A efetividade de cada mecanismo de captura de partículas, denominada de filtração, depende das forças de interação entre o meio poroso, o fluido que invade a formação e as partículas suspensas (Sharma e Yortsos, 1987). Em um processo de filtração, parâmetros como a velocidade, a concentração de partículas, a distribuição do tamanho de partículas, a distribuição de tamanho de poros, as energias de interação (partículaspartículas e partículas-poros) e a composição do fluido e das partículas injetadas, podem determinar o mecanismo de retenção de partículas mais efetivo (HERZIG et al., 1970, SHARMA E YORTSOS, 1987).

\section{METODOLOGIA}

\section{Caracterização do fluido de emulsão base n- parafina}

Para avaliar a potencialidade de risco ambiental presente no fluido foram empreendidos ensaios laboratoriais para determinação de suas características físicas (viscosidade e densidade), obedecendo aos procedimentos descritos na norma ISSO DIS 10414-2- Petroleum and natural gas industries - Field testing of drilling, bem como sua composição, particularmente os compostos de interesse a partir do emprego de cromatografia gasosa.

A determinação da viscosidade de um fluido é feita utilizando o funil Marsh, registrando-se o tempo em que $250 \mathrm{ml}$ de fluido leva para vazar pelo utensílio ou através da utilização de viscosímetro, no qual uma amostra é colocada sob pressão dentro de um recipiente do viscosímetro e é avaliado o tempo que o filtrado (parte líquida da lama) leva para passar pelo filtro do recipiente. A viscosidade é expressa em $\mathrm{cP}$ (centipoise). Determinação da massa específica de um determinado volume de fluido é obtida através de balança de lama e expressa em $\mathrm{g} / \mathrm{cm}^{3}, \mathrm{~kg} / \mathrm{m}^{3}, \mathrm{lb} / \mathrm{gal}$ ou lb/pé3.

A determinação da concentração de compostos monoaromáticos no fluido, que representam a parcela solúvel e potencialmente tóxica, foi realizada mediante uma técnica conservadora. Para tal fim, foi empregada uma amostra do fluido de emulsão base n-parafina hidrogenada fresca colocada em contato com água em um frasco hermeticamente selado, em volumes iguais e mantidos em agitação por 8 horas para assegurar que o equilíbrio de concentração entre ambos os fluidos fosse alcançado. A concentração resultante foi medida analisada por cromatografia gasosa.

\section{Simulação numérica multi-fásica de invasão do fluido na formação}

A modelagem matemática para a simulação da invasão de filtrado no reservatório tem fundamento físico definido pelas equações de conservação de massa para determinação de saturações e pressão juntamente com as equações da lei de Darcy (1856) para determinação dos fluxos das fases envolvidas. O perfil de saturação de filtrado no reservatório é obtido através do simulador INVASÃO, desenvolvido internamente na PETROBRAS, que utiliza e considera como abordagem numérica o escoamento bidimensional em coordenadas cilíndricas, bifásico, transiente, isotérmico e a condição de axisimetria do poço, conforme detalhado em Waldmann et al., 2011.

A estratégia adotada pelo simulador para resolver as equações diferenciais parciais de conservação de massa da fase óleo e conservação de massa global é aplicação do método de volumes finitos bastante utilizados para resolver problemas de engenharia.

\section{Simulação Numérica de Transporte de Benze- no}

Para a realização das simulações de migração de benzeno dentro do aquífero São Sebastião foi empregado o pacote computacional MT3DMS (ZHENG E WANG, 1999) que emprega a técnica numérica das Diferenças Finitas para a solução dos problemas envolvendo transporte de solutos.

Este código é resultado da aplicação do algoritmo de Diferenças Finitas para resulta da expressão generalizada da Equação Governante do Transporte de Solutos, em todas as células do modelo, podendo ser aproximado pelos valores de concentração em qualquer interface destas células, como descrito por Zheng e Wang (1999).

\section{RESULTADOS}

\section{Resultados da Caracterização do fluido de emulsão base n-parafina}

Análises do fluido de emulsão base nparafina indicam que o fluido é representado por uma mistura de compostos orgânicos contendo principalmente hidrocarbonetos parafínicos na faixa de $\mathrm{C}-13$ a C-18, sendo que os seus constituintes majoritários são representados pelos hidrocarbonetos na faixa C-14 e C-15, com participação de $63,67 \%$ e $24,30 \%$ na mistura, respectivamente (Figura 3). A n-parafina analisada, de 
densidade de $0,764 \mathrm{~g} / \mathrm{cm}^{3}$, denominada n-parafina hidrogenada, passa por um processo de hidrodesa- romatização, que visa eliminação da massa de compostos monoaromáticos presentes no fluido.

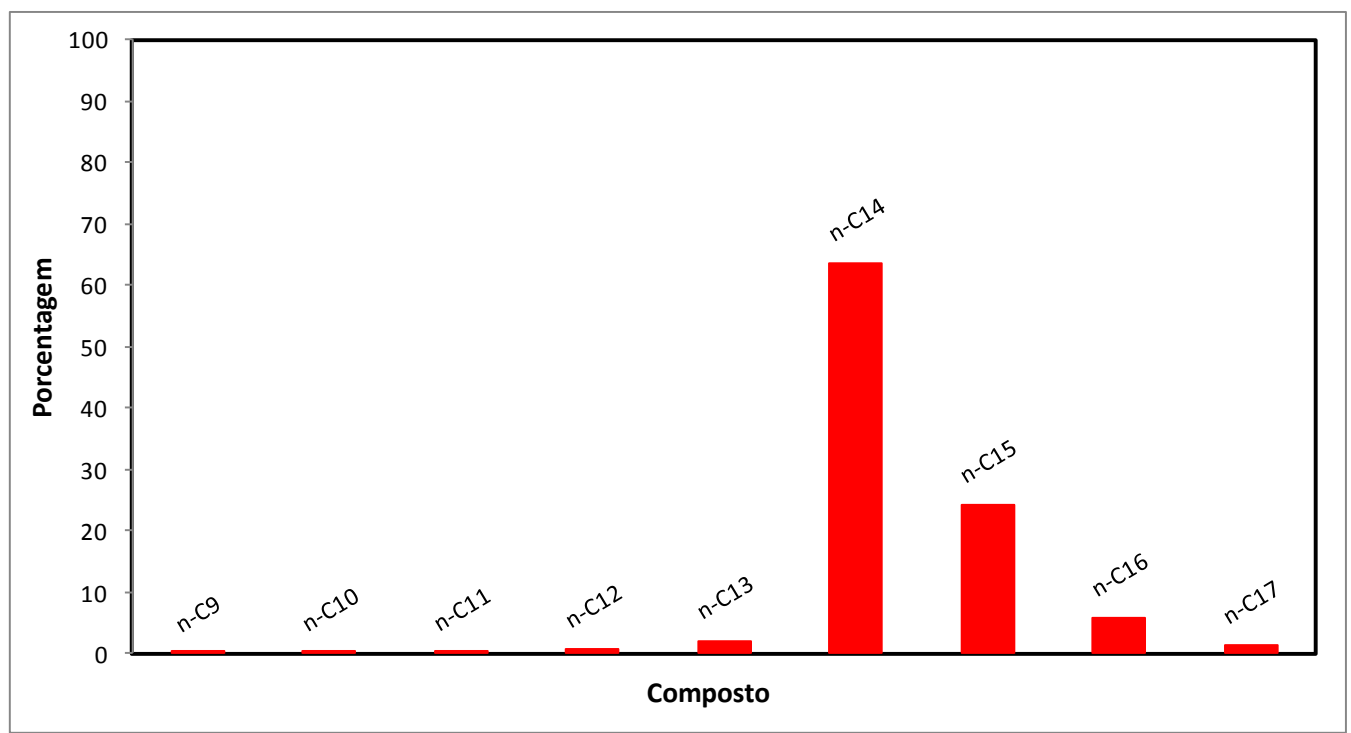

Figura 3 - Principais constituintes da n-parafina por carbonos na cadeia

Figure 3 - Main constituents of the n-paraffin by carbons in the chain

A Tabela 1 mostra resultados de análises cromatográficas na fase aquosa do fluido de emulsão base n-parafina, visando a determinação da massa de compostos monoaromáticos proveni- entes do fluido de emulsão base n-parafina. $\mathrm{Na}$ mesma Tabela 1 estão apresentados os limites de intervenção estabelecidos pela CETESB (2005).

Tabela 1 - Resultados de análises químicas para o fluido de emulsão base n-parafina Tabela 1 - Results of chemical analyzes for the emulsion fluid n-paraffin base

\begin{tabular}{lccc}
\hline \hline Composto & Resultado * & Limite de detecção* & $\begin{array}{c}\text { Limite de intervenção da } \\
\text { CETESB (2005)* }\end{array}$ \\
\hline \hline benzeno & 210 & 1 & 5 \\
tolueno & 11.440 & 1 & 700 \\
etilbenzeno & 2.310 & 1 & 300 \\
xilenos totais & 14.980 & 1 & 500 \\
\hline \hline
\end{tabular}

*resultados expressos em $\mu \mathrm{g} / \mathrm{l}$

\section{Resultados da simulação numérica multi-fásica de invasão do fluido na formação}

As simulações numéricas para determinação do perfil de invasão (perfil de saturação de filtrado no meio poroso) foram realizadas com base nos valores de permeabilidade de reboco, determinadas experimentalmente através de ensaios de filtração estática (WALDMANN et al., 2011), e com base nos dados de perfuração mostrados na Tabela 2. 
Tabela 2 - Base de dados para as simulações numéricas

Table 2 - Database for numerical simulations

\begin{tabular}{ccc}
\hline \hline Variável & Valores & Unidades \\
\hline \hline $\mathrm{K}_{\text {meio poroso }}$ & 750 & $\mathrm{mD}$ \\
$\mu_{\text {filtrado }}$ & $2,50 \times 10^{-03}$ & Pa.s \\
$\mu_{\text {água }}$ & $1,00 \times 10^{-03}$ & Pa.s \\
$\mathrm{r}_{\text {poço }}$ & $3,11 \times 10^{-01}$ & $\mathrm{~m}$ \\
$\mathrm{C}_{\mathrm{s}}$ & 8 & $\%$ \\
$\Delta \mathrm{P}$ & 350 & $\mathrm{psi}$ \\
Espessura da formação & 1100 & $\mathrm{~m}$ \\
Tempo & 1,5 & dias \\
\hline \hline
\end{tabular}

Onde o $\Delta \mathrm{P}$ representa o diferencial de pressão imposto entre o poço e a formação, $\mu_{\mathrm{f}} \mathrm{e}$ $\mu_{\text {água }}$ são respectivamente, a viscosidade efetiva do

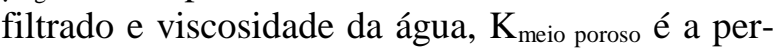
meabilidade do meio poroso, $\mathrm{r}_{\mathrm{poço}}$ é o raio do poço, $\mathrm{C}_{\mathrm{s}}$ é a concentração de sólidos no fluido, definida como a razão entre o volume de sólidos e o volume total (Volume de sólidos (Vs) + Volume de líquido (VL)).

As figuras a seguir ilustram os resultados de perfil de saturação de fluido e perfil de pressão no meio poroso como função raio do reservatório, cujo centro coincide com o eixo da perfuração do poço. Os resultados das simulações demonstram que quanto menor o valor da permeabilidade do reboco maior será a perda de carga e consequentemente menor será a invasão do filtrado do fluido de perfuração. Os resultados mostram a importância de um projeto de fluido adequado que garanta a formação de um reboco de baixa permeabilidade e que minimize o processo invasivo.

Para buscar alternativas que promovam a redução de permeabilidade do reboco e, consequentemente do volume de fluido que entra na formação, foram empreendidas simulações para os dois tipos de fluidos distintos, a primeira representada pelo fluido base n-parafina e a segunda representa pelo mesmo fluido com acrescido de uma concentração de $30,71 \mathrm{~g} / 1$ de de $\mathrm{CaCO}_{3}$.

As simulações foram realizadas para determinação do perfil de saturação do fluido na região em torno do poço, considerando-se uma permeabilidade da formação de 7,40 x $10^{-13} \mathrm{~m}^{2}$ ). Os resultados indicam que o potencial de invasão de fluido (filtrado) é baixo. É perceptível que no limite poço - formação, ou seja, no raio em torno de 0,31 metros (raio do poço) a saturação de fluido sempre será máxima, porém essa frente de saturação de filtrado não se propaga ao longo da formação (Figura 4).

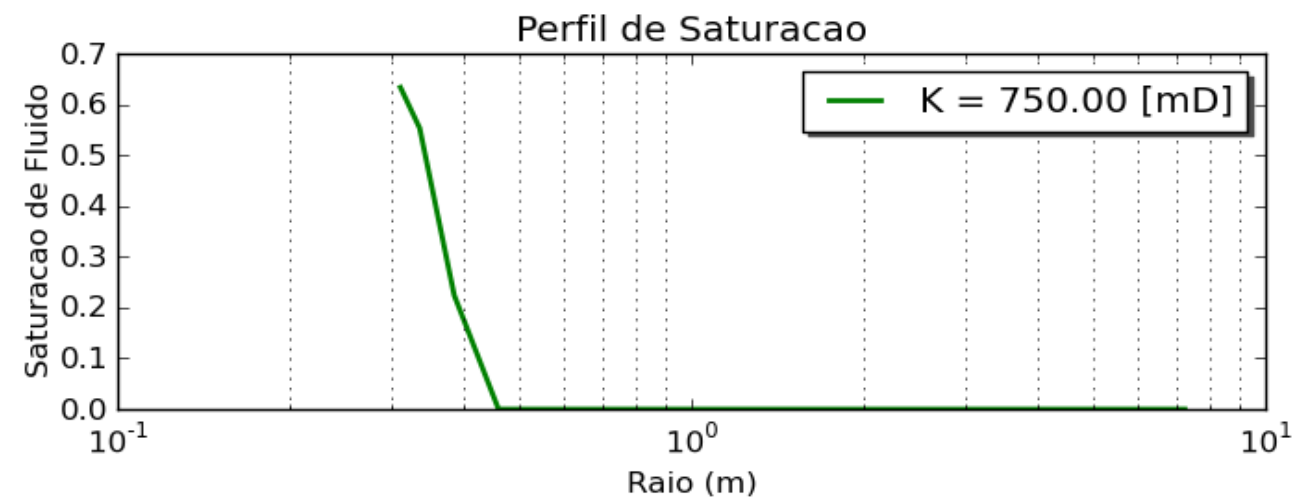

Figura 4 - Perfil de saturação 2D de filtrado no meio poroso - Fluido sintético $\mathrm{K}_{\text {reboco }}=2,87 \times 10^{-3} \mathrm{mD}$

Figure 4-2D profile of saturation of the filtrated in the porous medium - Synthetic Fluid Kreboco $=2.87 \times 10^{-3} \mathrm{mD}$ 
A Figura 5 ilustra perfil de invasão para o fluido sintético com adição de 30,71 g/l de carbonato de cálcio. Os resultados mostram que a saturação de fluido em $10 \mathrm{~cm}$ de formação $(0,41 \mathrm{me}-$ tros de raio) fica em torno de pouco menos de $1 \%$. Esta simulação indica que o uso de um agente obturante ajuda a reduzir a saturação e o volume de filtrado na formação.

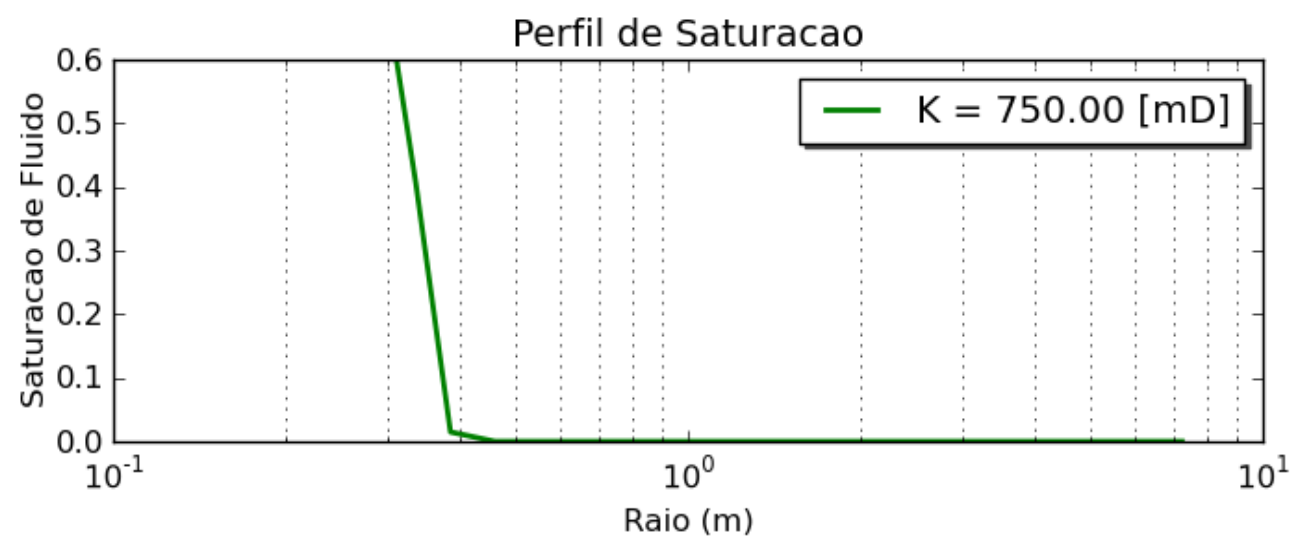

Figura 5 - Perfil de saturação 3D de filtrado no meio poroso - Fluido sintético + 70,31 g/l de $\mathrm{CaCO}_{3}$ $\mathrm{K}_{\text {reboco }}=1,85 \times 10^{-3} \mathrm{mD}$

Figure 5 - 2D profile of saturation of the filtrated in the porous medium - + Synthetic Fluid $70.31 \mathrm{~g} / 1$ $\mathrm{CaCO}_{3}-$ Kreboco $\mathrm{MD}=1.85 \times 10^{-3}$

\section{Resultados das Simulações Numéricas de Transporte de benzeno}

O modelo gerado visou a representação de uma porção correspondente às litologias arenosas da Formação São Sebastião, que representam a porção mais permeável do aquífero e na qual ocorre principalmente o transporte de solutos presentes no fluido de emulsão base n-parafina. $\mathrm{O}$ domínio do modelo adotado foi representado em uma malha bidimensional, com uma área de $24 \mathrm{x}$ 24 m, discretizada em 200 colunas e 200 linhas, com espaçamento de $0,12 \mathrm{~m}$ entre os nós.

Assumindo-se que durante o processo de perfuração, com a circulação do fluido de perfuração, existe o influxo contínuo de filtrado e, consequentemente, de benzeno presente neste fluido, foi imposta uma condição de concentração constante na porção correspondente à zona invadida. Foi empregada a premissa de que durante o período em que ocorre a perfuração do poço, a região na formação geológica onde existiu a intrusão contínua de fase orgânica do fluido de perfuração representou uma fonte de concentração constante com valores de $210 \mu \mathrm{g} / \mathrm{L}$ de benzeno, baseando-se nos resultados analíticos apresentados na Tabela 1.

Foi gerado um campo de condutividades hidráulicas pseudo-aleatório (Figura 6), com valor médio de $2,7 \times 10^{-5} \mathrm{~m} / \mathrm{s}$. De modo similar ao modelo de fluxo multifásico, foi imposto uma condição de fluxo axissimétrica bidimenisonal, com um gradiente hidráulico de 0,0035 , determinado por Cunha et al., (1986), do centro para as bordas do modelo a partir da inserção de condições de contorno de carga hidráulica fixa nas extremidades e no centro da área simulada. Com o objetivo de se prever a evolução diária das concentrações, o período empregado nas simulações foi de 60 dias, com passo de tempo de 1 dia. 


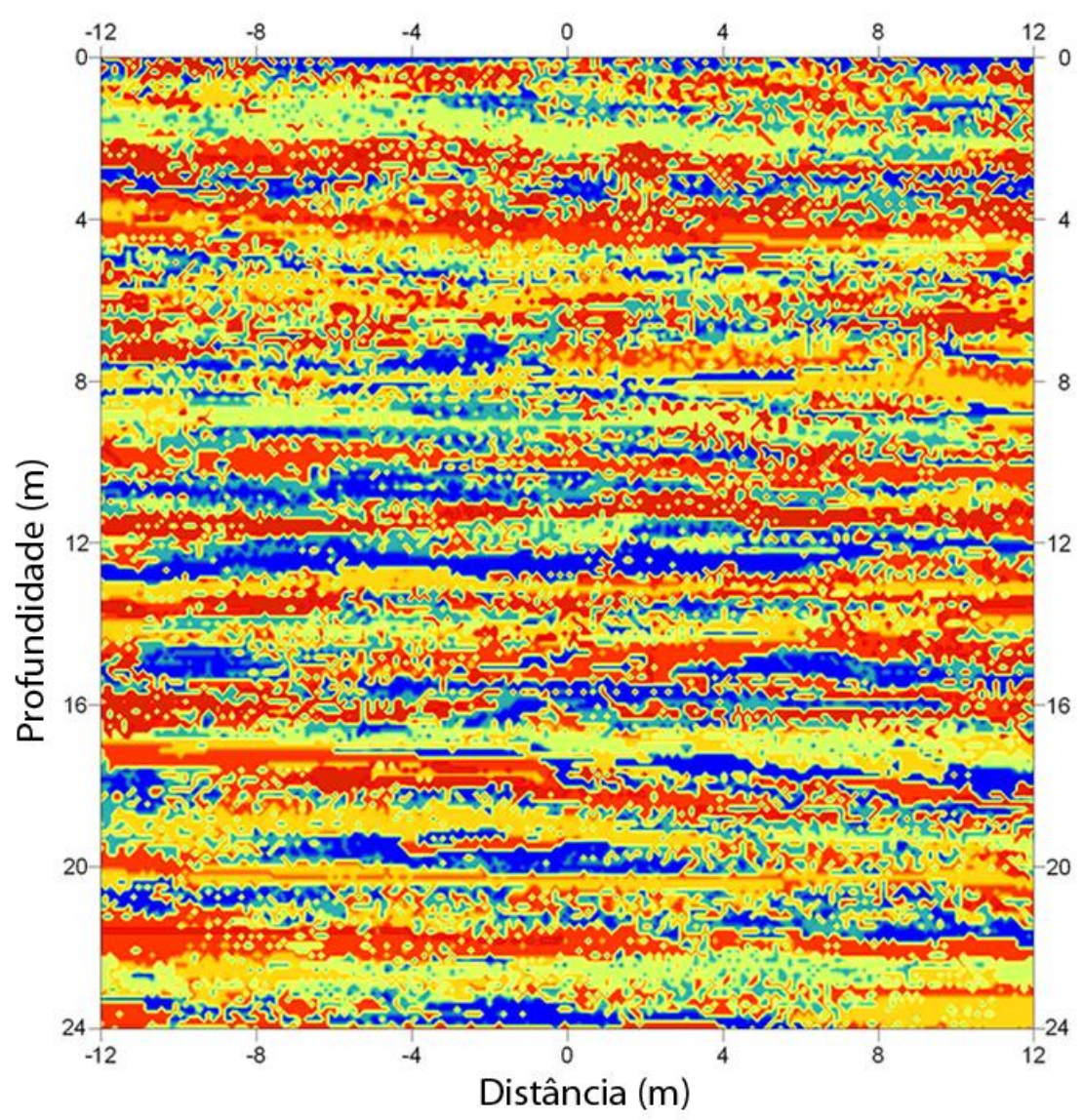

Figura 6 - Distribuição espacial dos valores de condutividade hidráulica pseudo-aleatórios em pregadas no modelo

Figure 6 - Spatial distribution of the pseudo-random hydraulic conductivity values used in the model

As premissas adotadas no modelo foram impostas com a finalidade de gerarem resultados conservadores, isto é, os piores cenários possíveis de contaminação. Conceitualmente foi admitido que durante a injeção de fluido de emulsão base n-parafina para a formação, a fração não aquosa da mistura é agregada à sua matriz por forças eletrostáticas, formando o reboco, que diminui a permeabilidade da formação e o filtrado (fração aquosa da mistura) do fluido de emulsão base nparafina ingresse para a formação portando contaminantes de interesse ambiental. Uma vez cessada a pressurização do poço e interrompida o ingresso do filtrado para a formação, existe a interrupção do fluxo de contaminantes para o aquífero, tendo em vista que a solubilização do fluido já presente nas adjacências do poço é nula e não existe o fluxo de fluido do poço para a formação. Para simular tal situação, foi imposto uma condição de concentração especificada durante os 3 dias que representam um período superior ao necessário para a conclusão da perfuração e com- plementação, com seu revestimento. Após este período, com a interrupção do influxo de fluido de emulsão base n-parafina para a formação, é imposto uma condição de concentração nula.

Admitiu-se que a pressão aplicada ao poço pela presença do fluido de perfuração gera um gradiende hidráulico local com conformação radial, o que promove um incremento na abrangência do espalhamento dos contaminantes. Como demonstrado anteriormente nos resultados das simulações realizadas para prever o comportamento do fluido de emulsão base n-parafina que invade a formação, para uma permeabilidade de $750 \mathrm{mD}$, a zona invadida terá um diâmetro aproximado de $15 \mathrm{~cm}$, com saturação variando dentro de um intervalo de 0,6 adjacente ao poço se reduzindo a 0 nas porções mais distantes. Contudo, foi assumida uma fonte de $0,15 \mathrm{~m}$ de largura e $100 \%$ de saturação dos poros com o fluido, o que resulta em um incremento significativo na massa de contaminantes (Figura 7). 

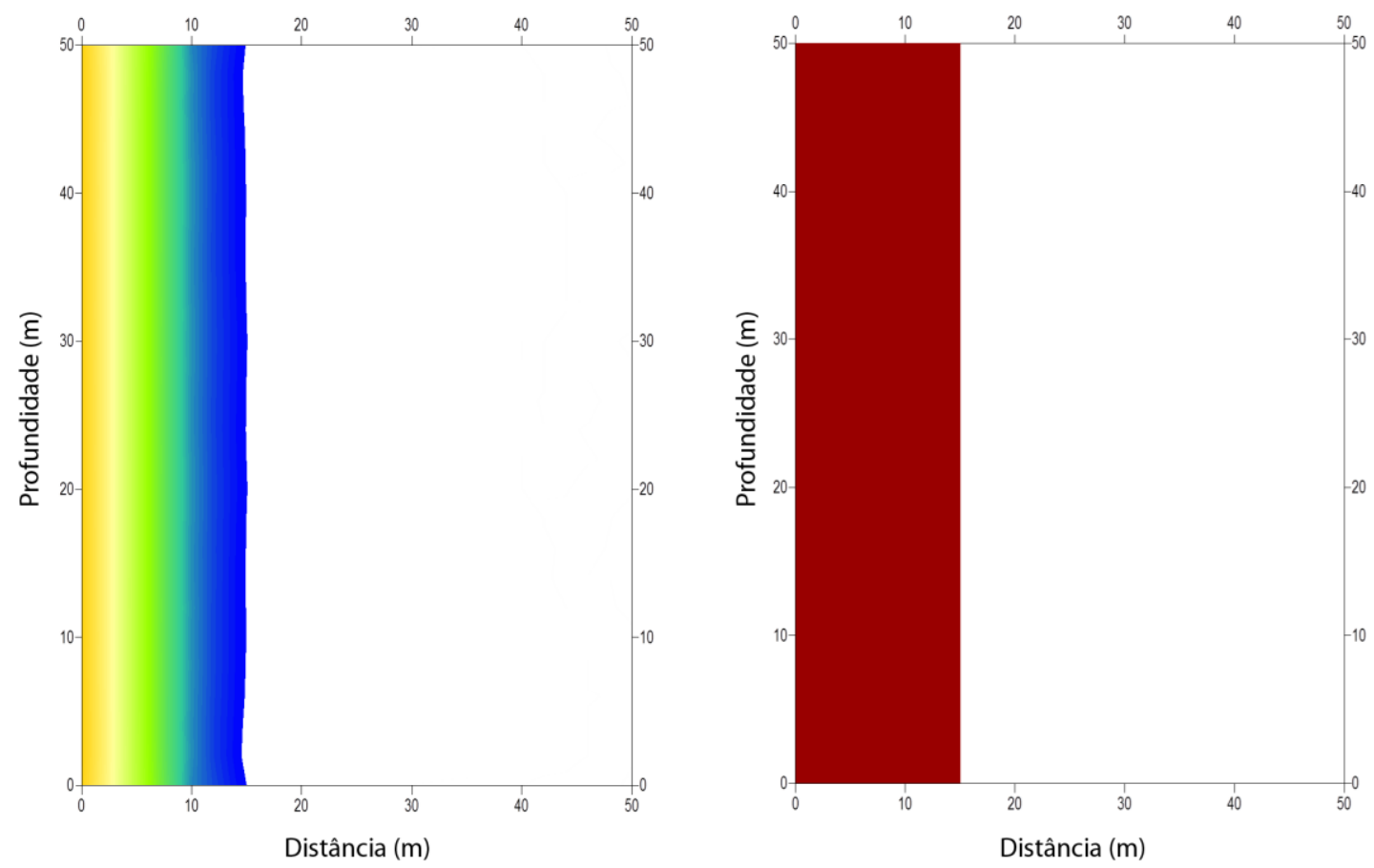

Saturaçăo de n-parafina

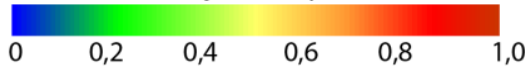

Figura 7 - Comparação entre a saturação real de n-parafina nas proximidades do poço e a saturação admitida na simulação

Figure 7 - Comparison between the actual saturation of n-paraffin in the vicinity of the well and saturation assumed in the simulation

Adotou-se um valor de dispersividade de $0,15 \mathrm{~m}$, que representa $10 \%$ da trajetória de fluxo no período simulado, adotando a relação proposta por Lallemand-Barres e Peaudecerf (1978). Arbitrariamente foi adotado um valor de 50 dias para o tempo de meia-vida do benzeno no aquífero São Sebastião, valores superiores aos descritos por Howard et al., (1991), cujos valores de meia-vida para benzeno sob condições aeróbicas variam dentro de um intervalo de 4,95 a 16,11 dias.

Assumindo-se que durante o processo de perfuração, existe o influxo de fluido de emulsão base n-parafina e, consequentemente, de benzeno presente neste fluido, para o aquífero São Sebastião, foi imposto uma condição de concentração constante na porção correspondente à zona invadida (Figura 8).
O início da simulação até o $3^{\circ}$ dia corresponde ao período assumido onde se procede a perfuração do poço e há o ingresso do filtrado do fluido de perfuração para a formação e, consequentemente, do benzeno presente na n-parafina; para o aquífero. Uma vez cessada a perfuração do poço com a introdução do seu revestimento, assume-se que o influxo de n-parafina é interrompido, não mais havendo ingresso de benzeno para o aquífero, a partir deste período. Dentro deste contexto, a partir do $4^{\circ}$ dia impõe-se que a concentração na fonte é nula em função da ausência de entrada de fluido de perfuração no interstício poroso do aquífero. Deste modo as condições de contorno de concentração especificada para benzeno podem ser representada pela Equação 1.

$$
C(0, y, z, t)=\left\{\begin{array}{l}
C_{0}=210 \mu g / L, 0<t \leq 3 \\
C_{0}=0, t>3
\end{array}\right.
$$

As simulações permitem prever a evolução temporal da pluma de benzeno no aquífero São Sebastião. Os resultados das simulações ilustradas nas Figuras 8 a 12 indicam que após a finalização e interrupção da injeção de n-parafina na formação, a liberação potencial de benzeno para a água subterrânea é cessada e a tendência verifica- da é o rápido declínio nas concentrações deste composto em função da diluição durante o processo de dispersão mecânica e da biodegradação. A extensão máxima da pluma foi de 4 metros a partir do centro do poço (Figura 12), antes das concentrações declinarem para valores abaixo dos limites de intervenção da CETESB (2005). 


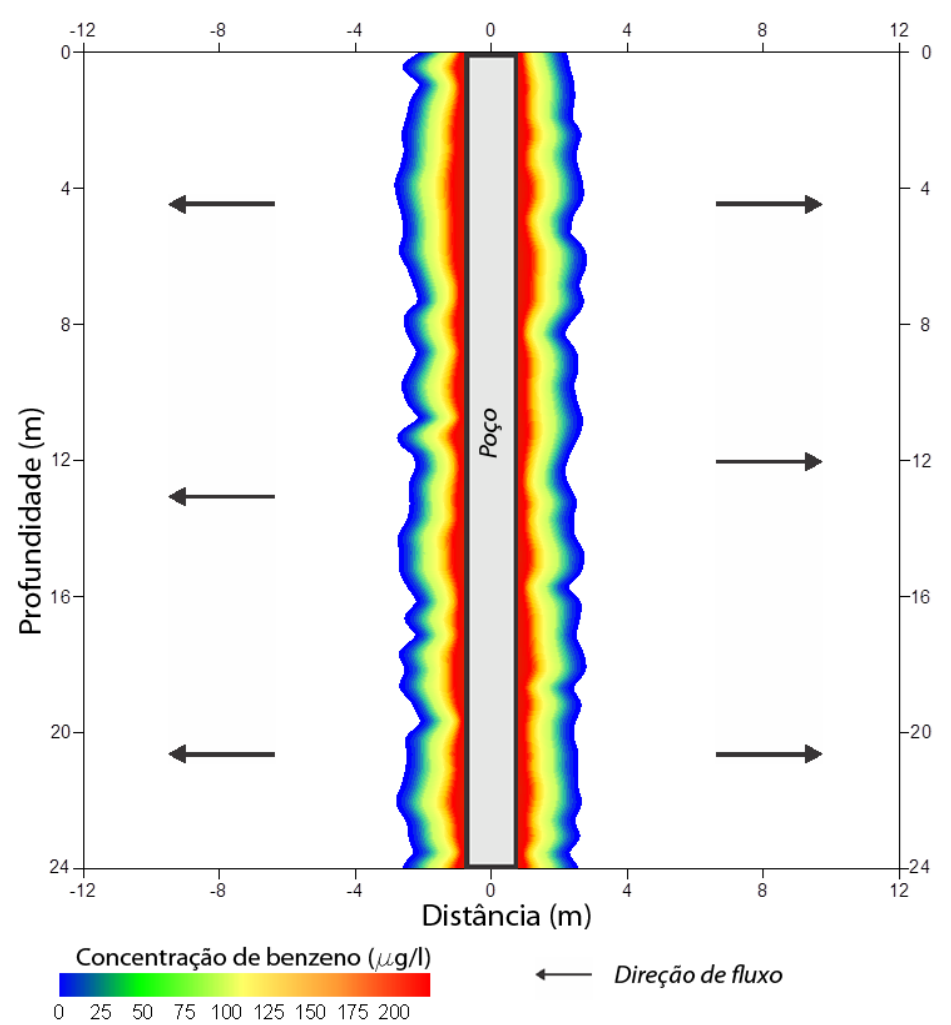

Figura 8 - Distribuição das concentrações de benzeno no $1^{\circ}$ após o início da simulação Figure 8 - Distribution of concentrations of benzene in day 1 after the start of the simulation

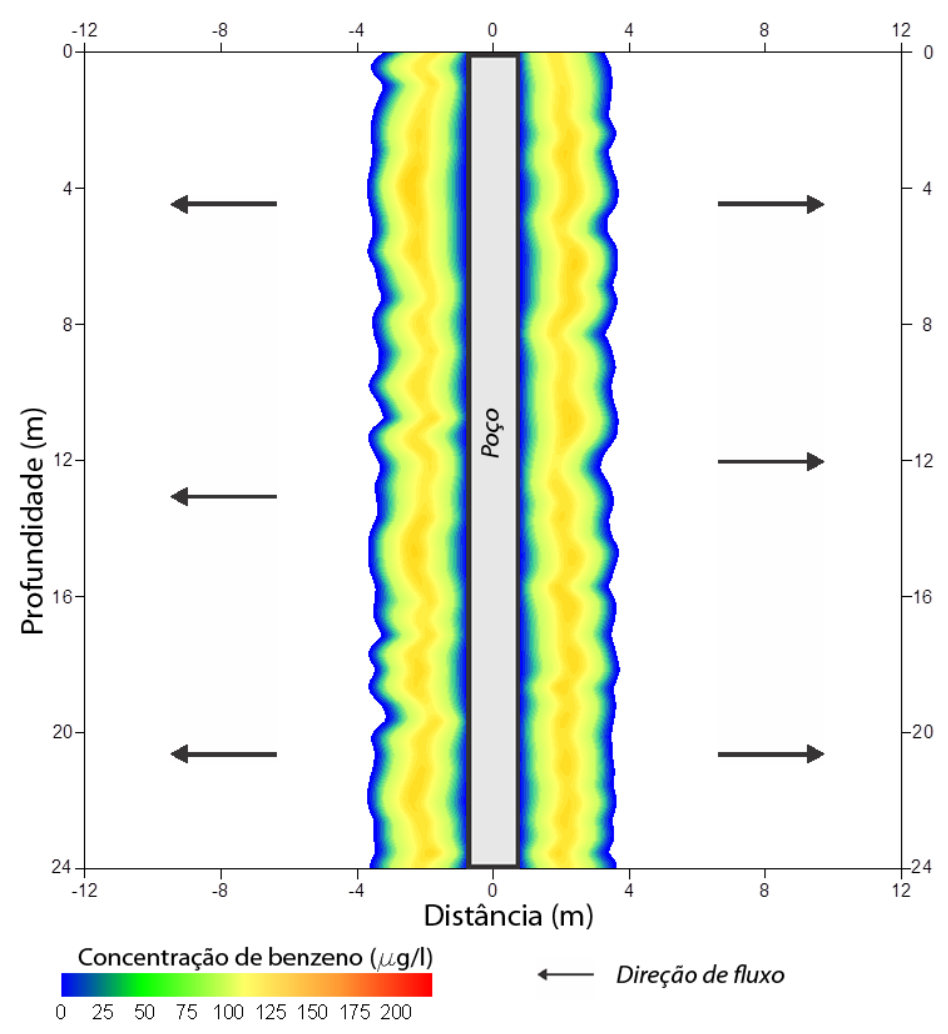

Figura 9 - Distribuição das concentrações de benzeno no $4^{\circ}$ após o início da simulação Figure 9 - Distribution of concentrations of benzene in day 4 after the start of the simulation 


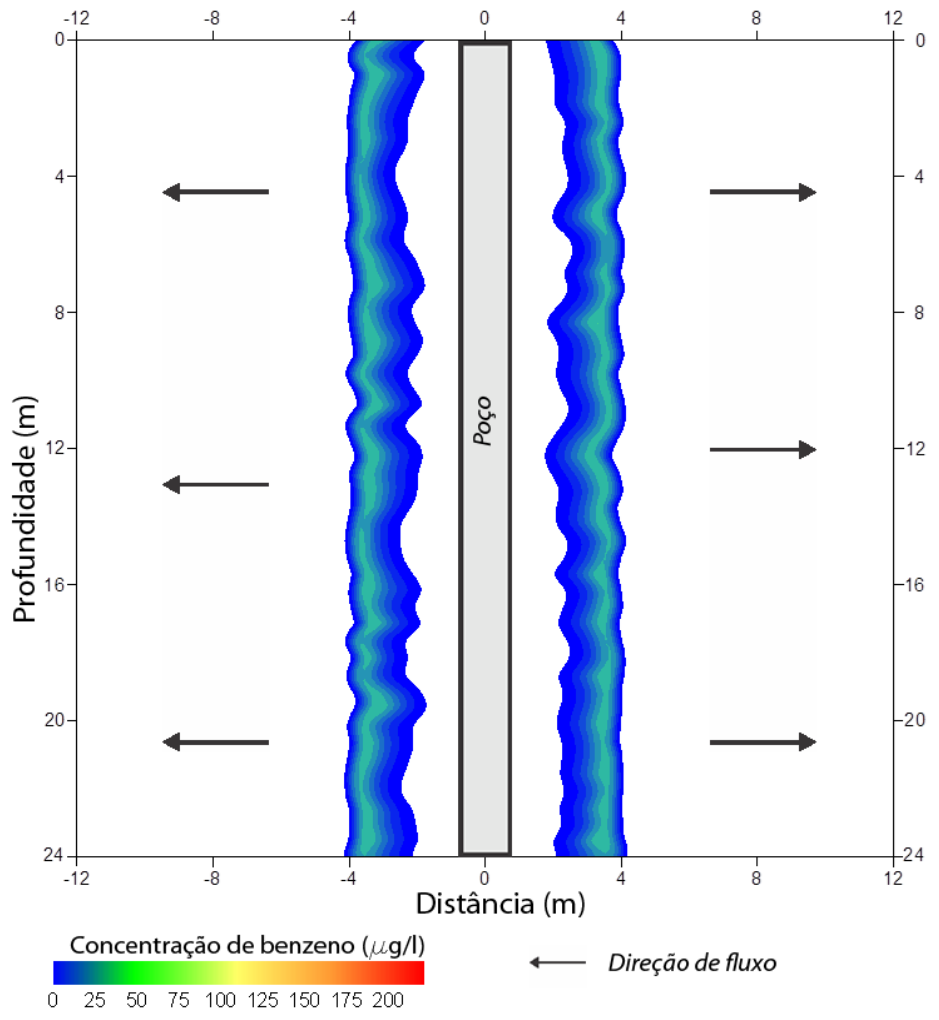

Figura 10 - Distribuição das concentrações de benzeno no $12^{\circ}$ após o início da simulação Figure 10 - Distribution of benzene concentrations in the day 12 after the start of the simulation

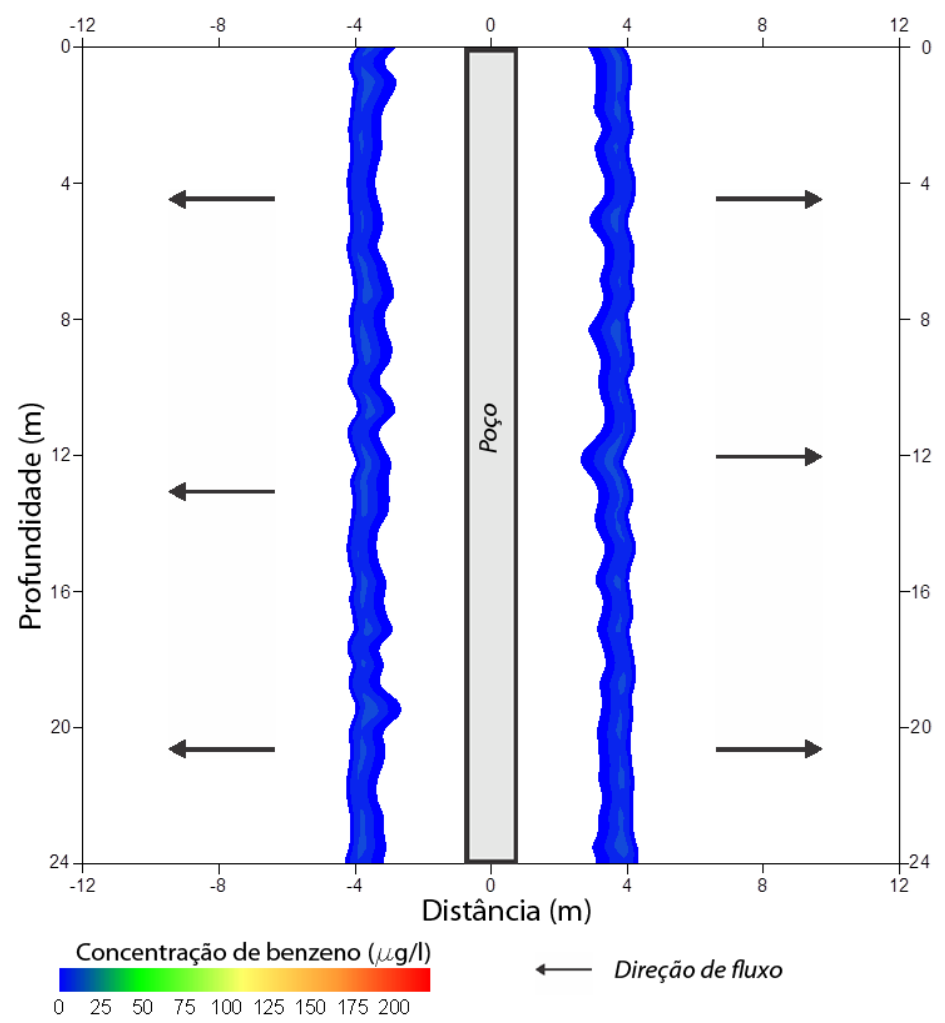

Figura 11 - Distribuição das concentrações de benzeno no $20^{\circ}$ após o início da simulação Figure 11 - Distribution of benzene concentrations in day 20 after the start of the simulation 


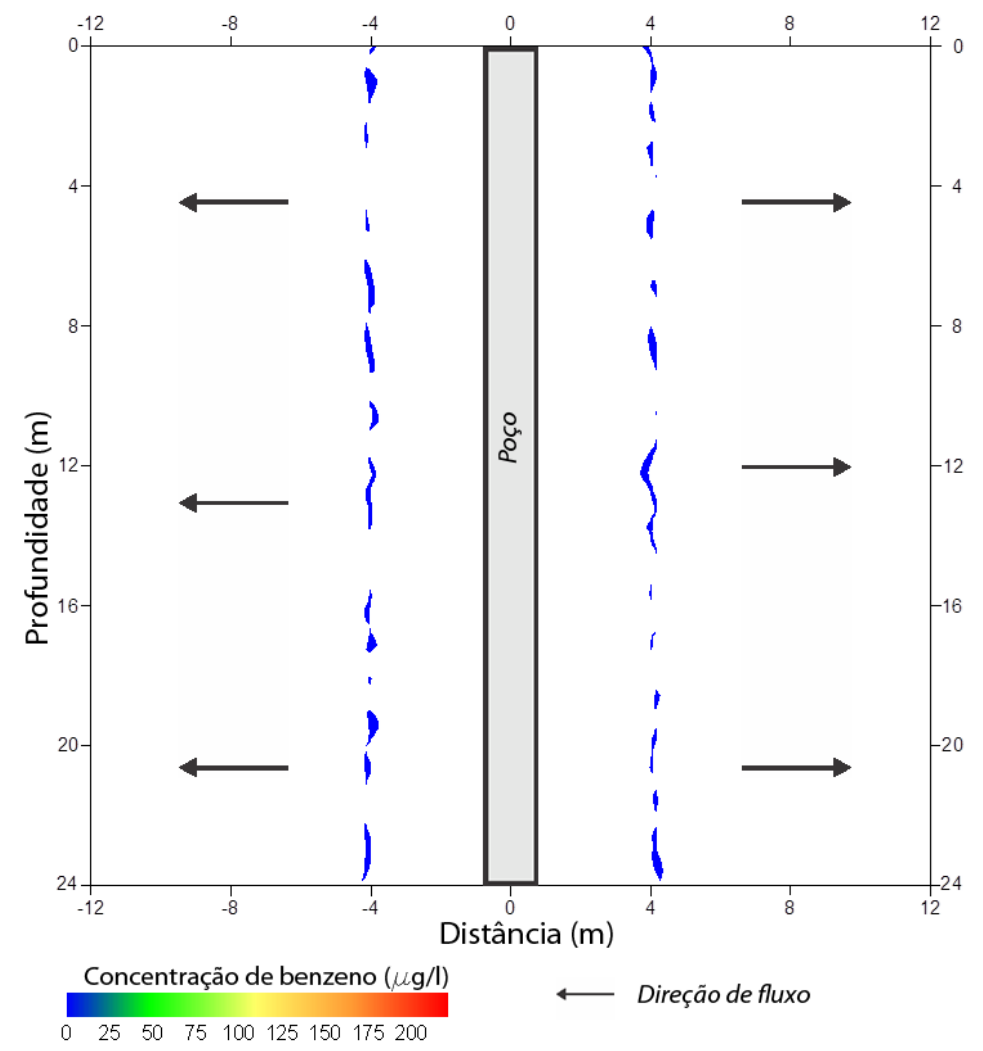

Figura 12 - Distribuição das concentrações de benzeno no $40^{\circ}$ após o início da simulação Figure 12 - Distribution of benzene concentrations in day 40 after the start of the simulation

\section{CONCLUSÕES}

As simulações numéricas para avaliar a invasão de fluido para a formação mostram que nas condições normalmente observadas no Aquífero São Sebastião, a invasão pelo filtrado atingirá a distância de $0,11 \mathrm{~m}$ a partir da parede da perfuração. A formação do reboco, com a consequente redução da permeabilidade na parede do poço, limita o volume do fluido passível de invadir a formação. A adição de material particulado como o $\mathrm{CaCO}_{3}$ propicia uma redução mais significativa e eficiente na permeabilidade do reboco, o que gera uma restrição adicional ao influxo do filtrado para a formação.

As premissas empregadas nas simulações

\section{REFERÊNCIAS}

BARCElOS, A. A.; CASSOL, E. A; DENARDIN, J. E. Infiltração de água em um latossolo vermelho-escuro sob condições de chuva intensa em diferentes sistemas de manejo. Revista Brasileira de Ciência do Solo, v.23, p. 35-43, 1999.

BARRETO, C. E. A. G. Balanço hídrico em zona de afloramento do Sistema Aquífero Guarani a partir de monitoramento hidrogeológico em bacia representativa. 2005. 270 p. Dissertação (Mestrado em Engenharia) - Escola de Engenharia de São Carlos, Universidade São Paulo (USP), São Carlos, 2006. de transporte de contaminantes admitiram um conjunto de parâmetros conservadores, que visaram a previsão de cenários pessimistas do ponto de vista de migração de contaminantes. A adoção destas premissas incrementou em quantidades superiores a 1.000 vezes a massa de contaminantes que ingressaram no aquífero em comparação à situação mais realista, como pode ser observado no trabalho de Vaqueiro (2006). Dentro dessas premissas, o benzeno não excede uma distância de 4,2 metros a partir da fonte, verificando-se um rápido decréscimo em suas concentrações, devido à dispersão hidrodinâmica e biodegradação deste composto.

BOMFIM, E. P.; MOLINA, E. C. Análise da variação dos elementos do campo de gravidade na região do Aquífero Guarani a partir dos dados GRACE. Revista Brasileira de Geofísica, v. 27, p. 17-34, 2009.

FREITAS, R. M.; ARAI, E.; ADAMI, M.; SOUZA, A. F.; SATO, F. Y.; SHIMABUKURO, Y. E.; ROSA, R. R.; ANDERSON, L. O.; RUDORFF, B. F. T. Virtual laboratory of remote sensing time series: visualization of MODIS EVI2 data set over South America. Journal of Computational Interdisciplinary Sciences, v. 2, p. 57-68, 2011. doi: 10.6062/jcis.2011.02.01.0032. http://www.epacis.net/jcis 
JIANG, Z.; HUETE, A. R.; DIDAN, K.; MIURA T. Development of a two-band Enhanced Vegetation Index without a blue band, Remote Sensing of Environment, v. 112, p. 3833-3845, 2008.

HEALY, R. W. Estimating groundwater recharge. Cambridge: Cambridge University Press, 2010. 245p.

HUETE, A. R.; DIDAN, K.; MIURA, T. RODRIGUEZ, E. P.; GAO, X.; FERREIRA, L.G. Overview of the radiometric and biophysical performance of the MODIS vegetation indices. Remote Sensing of Environment, v. 83, p. 195-213, 2002.

INPE (INSTITUTO NACIONAL DE PESQUISAS ESPACIAIS). Monitoramento da floresta amazônica por satélite, Projeto PRODES, 2008. Disponível em: http://www.obt.inpe.br/prodes/r2007.htm. Acesso em: 12 Mar 2013.

JUSTICE, C. O.; VERMOTE, E. F.; TOWNSHEND, J. R. G.; DEFRIES, R.; ROY. D. P.; HALL, D. K.; SALOMONSON, V.; PRIVETTE, J. L.; RIGGS, G.; STRAHLER, A.; LUCHT, W.; MYNENI, B.; KNYAZIKHIN, Y. RUNNING, W. S.; NEMANI, R. R.; WAN, Z.; HUETE, A. R.; LEEUWEN, W. V.; WOLFE, R. E.; GIGLIO, L. MULLER, J. P.; LEWIS, P.; BARNSLEY, M. The Moderate Resolution Imaging Spectroradiometer (MODIS): land remote sensing for global changing research. IEEE Transaction on Geosciences and Remote Sensing, v. 36, p. 1228-1247, 1998.

JUSTICE, C. O.; TOWNSHEND, J. R. G.; VERMOTE, E. F.; MASUOKA, E.; WOLFE, R. E.; SALEOUS, N.; ROY. D. P.; MORISETTE, J. T. An overview of MODIS land data processing and product status. Remote Sensing of Environment, v. 83, p. 3-15, 2002.

KNOTTERS, M.; VAN WALSUM, P. E. V. Estimating fluctuation quantities from time series of water-table depths using models with a stochastic component. Journal of Hydrology, v.197, p.25-46, 1997.

LANDIM, P. M. B. Análise de dados geológicos. São Paulo: EDUNESP, 1998.

LATORRE, M. L.; SHIMABUKURO, Y. E.; ANDERSON, L. O. Produtos para ecossistemas terrestres - MODLAND. In: RUDORFF, B. F. T.; SHIMABUKURO, Y. E.; CEBALLOS, J. C. (org.) O sensor MODIS e suas aplicações ambientais no Brasil. São José dos Campos: A. Silva Vieira Editora, 2007. p. 23-35.

LE MAITRE, D. C.; SCOTT, D. F.; COLVIN, C. A review of information on interactions between vegetation and groundwater. Water SA, v. 25, p. 137-152, 1999.

MANZIONE, R. L., WENDLAND, E.; TANIKAWA, D. H. Stochastic simulation of time-series models combined with geostatistics to predict water-table scenarios in a Guarani Aquifer System outcrop area, Brazil. Hydrogeology Journal, v. 20, p. 1927-1937, 2012.

MESTRINHO, S. S. P. Monitoramento em água subterrânea. In: FEITOSA, F.A.C.; MANOEL FILHO, J.; FEITOSA, E. C.; DEMETRIO, J. G. A. Hidrogeologia: Conceitos e aplicações. CPRM/LABHID, Rio de Janeiro, 2008. p. 673-686.

MOREIRA, M. A.; ADAMI, M.; RUDORFF, B. F. T. Anál- ise espectral e temporal da cultura do café em imagens Landsat. Pesquisa Agropecuária Brasileira, Brasília, v. 39, n. 3, p. 223-231, 2004.

NETER, J.; KUTNER, M. H.; NACHTSHEIM, C. J. \& WASSERMAN, W., eds. Applied linear statistical models. McGraw-Hill, Chicago, 1996. 1408p.

RUDORFF, B. F. T.; AGUIAR, D. A.; SILVA, W. F.; SUGAWARA, L. M.; ADAMI, M.; MOREIRA, M. A. Studies on the Rapid Expansion of Sugarcane for Ethanol Production in São Paulo State (Brazil) Using Landsat Data. Remote Sensing, v. 2, p. 1057-1076, 2010. doi: 10.3390/rs2041057.

RUDORFF, B. F. T.; ADAMI, M.; AGUIAR, D. A.; MOREIRA, M. A.; MELLO, M. P.; FABRINI, D.; AMARAL, D. F.; PIRES, B. M. The Soy Moratorium in the Amazon biome monitored by remote sensing. Remote Sensing, v. 3, p. 185-202, 2011. doi: 10.3390/rs3010185

SCANLON, B. R; REEDY, R. C.; STONESTROM, D. A.; PRUDIC, D. E.; DENNEHY, K. F. Impact of land use and land cover change on groundwater recharge and quality in the southwestern US. Global Change Biology, v. 11, p. 1577-1593, 2005.

SHIKLOMANOV, I. World Water Resources. A new appraisal and assessment for 21st century. Paris: International Hydrological Programme/UNESCO, 1998. 37p.

SMITH, D. M., INMAN-BAMBER, N. G., THORBURN, P. J. Growth and function of the sugar cane root system. Field Crops Research, v. 92, p. 169-183, 2005.

SOARES, J. V.; BATISTA, G. T.; SHIMABUKURO, Y. E. Histórico e descrição. In: RUDORFF, B. F. T.; SHIMABUKURO, Y. E.; CEBALlOS, J. C. (org.) O sensor MODIS e suas aplicações ambientais no Brasil. São José dos Campos: A. Silva Vieira Editora, 2007. p. 3-21.

VAERET, L.; KELBE, B.; HALDORSEN, S.; TAYLOR, R. $\mathrm{H}$. A modeling study of the effects of land management and climatic variations on groundwater inflow to Lake St Lucia, South Africa. Hydrogeology Journal, v. 17, p. 1949-1967, 2009.

VON ASMUTH, J.R., MAAS, K., BAKKER, M., PETERSEN, J. Modeling time series of ground water head fluctuation subjected to multiple stresses. Ground water, v. 46, p. 30-40, 2008.

VÖRÖSMARTY, C.; LETTENMAIER, D.; LEVEQUE, C.; MEYBECK, M.; PAHL-WOSTL, C.; ALCAMO, J.; COSGROVE, W.; GRASSL, H.; HOFF, H.; KABAT, P.; LANSIGAN, F.; LAWFORD, R.; NAIMAN, R. Humans transforming the global water system. Eos, v. 85 , p. 509-520, 2004.

WENDLAND, E., BARRETO, C. E. A. G., GOMES, L. H. Water balance in the Guarani Aquifer outcrop zone based on hydrogeologic monitoring. Journal of Hydrology, v. 342, p. 261-269, 2007.

COSTA, I. P.; MILHOMEM, P. S.; BUENO, G. V.; LIMA E SILVA, H. S. R.; KOSIN, M. D. Sub-bacias de Tucano Sul e Central. In: MILANI, E. J. (Org), Bacias Sedimentares Brasileiras - Cartas Estratigráficas. Boletim de Geociências da Petrobras, Rio de Janeiro, v. 15, n. 2, p. 433-443. 2007. 
CETESB - Companhia de Tecnologia de Saneamento Ambiental "Relatório de Estabelecimento de Valores Orientadores para Solos e Águas Subterrâneas no Estado de São Paulo" CETESB; 2005.

CUNHA, J.E.M; NEGRÃO,F.I. \& SANTOS,P.R.P. Panorama atual das águas subterrâneas no Estado da Bahia.In: CONGRESSO BRASILEIRO DE ÁGUAS SUBTERRÂNEAS, 4,1986, Brasília.Anais : ABAS ,1986, p. 80-95.

DARCY, H. Les Fontaines Publiques de la Ville de Dijon. Dalmont, Paris. 647 p. \& atlas. 1856

DARLEY, H.C.H. e GRAY, G. R., Composition and properties of drilling and completion fluids, Fifth Edition, Gulf Publishing Company, Houston, Texas, 1988.

FETTER, C.W. Contaminant Hydrogeology. Macmillan Publishing Company, New York, 458pp. 1993.

HERZIG, J.P., LECLERC, D.M. e le GOFF, P. Flow of Suspensions through Porous Media - Application to Deep Filtration, Industrial and Engineering Chemistry, v. 62(8), p 8-35. 1970.

HOWARD, P. H.; BOETHLING, R. S.; MEYLAN, W. M. e MICHALENKO, E. M. Handbook of Environmental Degradation Rates. Lewis Publishers, Inc. Chelsea, MI, EUA. 1991.

LALLEMAND-BARRES, P. E PEAUDECERF, P. Reserche des relations entre la valeur de la dispersivite macroscopique d'un milieu aquifere, ses mItres caracteristques et les conditions de mesure, etude bibiliographique. Bulletin, Bureau de Recbercbes Geologques et Minieres. Sec. 3/4, p 277-287, 1978.

LEÃO, M.R.C. Aspectos da circulação da água no aqüífero São Sebastião .2003.71 f. Dissertação de Mestrado ( Pós Graduação em Geofísica)-Universidade Federal da Bahia,Salvador, 2003.
LIMA, H. Fundamentos de Perfuração. Apostila do Curso de Formação de Engenheiros de Petróleo da Petrobras,Centro de Desenvolvimento de Recursos Humanos Norte-Nordeste, Salvador, 2001.

PETROBRAS. Mapa geológico da bacia do Recôncavo. Escala1:1.000.000,Salvador,1968.

SHARMA, M. M.; YORTSOS, Y.C. Transport of Particulate Suspensions in Porous Media: Model Formulation. AlChE Journal. V.33(10), p 1636. 1987

VALADÃO NETO, O. Estudo do Aqüífero São Sebastião (Kss) na Bacia Sedimentar do Recôncavo. Secções Geológicas a partir da interpretação de perfis de poços de petróleo da Petrobrás. Trabalho inédito. PETROBRÁS, Salvador, Bahia. 2007.

VAQUEIRO, R.L.C. Avaliação de contaminação de aquíferos porosos a partir da perfuração de poços de petróleo utilizando fluido n-parafina. Dissertação de Mestrado - Programa de Pós-graduação em Recurso Minerais e Hidrogeologia, São Paulo, São Paulo, 2006.

WALDMANN, A. T. A. (2005), Mecanismos que Governam a Efetividade de Agentes Obturantes no Controle da Invasão de Fluidos de Perfuração na Rocha Reservatório de Petróleo, Dissertação de Mestrado, PUC - Rio, Departamento de Engenharia Mecânica, 96p. 2005

WALDMANN A.T.A, MARTINS A.L. e DANNENHAUER, C; Understanding Drill In Fluid Invasion into Multi Layer Reservoirs Satured by Compressible Fluids (SPE 144156), apresentado no SPE European Formation Damage Conference, Noordwijk, Holanda, 7 a 10 de Junho de 2011.

ZHENG, C. e WANG, P. MT3DMS: A Modular ThreeDimensional Multispecies Transport Model for Simulation of Advection, Dispersion, and Chemical Reactions of Contaminants in Groundwater Systems; Documentation and User's Guide. US Army Corps of Engineers Engineer Research and Development Center (1999). 